\title{
Quantificação dos estádios do ciclo espermatogênico em touros de raças sintéticas com e sem alteração na qualidade seminal
}

\author{
Staging spermatogenic cycle in synthetic bulls with normal and altered semen quality
}

\author{
Marilise Mesquita Horn ${ }^{1}$ José Carlos Ferrugem Moraes ${ }^{2}$ Maria Isabel Albano Edelweiss ${ }^{3}$
}

RESUMO

O objetivo deste estudo foi avaliar qual a freqüencia dos túbulos seminiferos nos diferentes estádios do ciclo espermatogênico em touros de duas raças sintéticas, sendo 12 Braford e 8 Brangus-Ibagé, classificados em aptos (grupo A) e inaptos (grupo B) à reprodução, de acordo com o exame andrológico. Os estádios avaliados foram representativos das fases proliferativa (estádio I), meiótica (estádio II) e de maturação (estádio III) da espermatogênese. Os touros Braford apresentaram freqüencias diferentes entre os grupos $A$ e $B$ nos estádios II e III. Os touros Brangus-Ibagé apresentaram diferenças entre os grupos apenas para o estádio II. Os resultados indicam que nas fases iniciais do ciclo espermatogênico (estádio I), os touros de raças sintéticas, classificados quanto à qualidade seminal, apresentam gametogênese semelhante. Nas fases em que ocorrem as divisões meióticas (estádio II) e a maturação das espermátides (estádio III), manifestam-se as alterações na espermatogênese que respondem pela classificação diferencial dos touros. $O$ uso do presente agrupamento de estádios do ciclo espermatogênico proporciona uma prática maneira de avaliar a cinética do epitélio germinativo em touros aptos e inaptos à reprodução.

Palavras-chave: avaliação histológica, espermatogênese, touros sintéticos.

\section{ABSTRACT}

This study investigates the frequency of different stages of spermatogenic cycle in synthetic bulls, being 12 from Braford and 8 from Brangus-Ibagé breed with normal and altered semen quality, classified as sound (Group A) and unsound (Group B) animals by andrological examination.
The staging criteria includes the proliferative (stage I), meiotic (stage II) and the maturation (stage III) periods of the spermatogenesis. The Braford bulls present different frequencies between groups within stages II and III. Among Brangus-Ibagé bulls there are different frequencies between groups just for stage II. The results indicate that spermatogenesis progress adequately in the stage I on synthetic bulls with different semen quality. During the period in which meiotic divisions (stage II) and spermatid maturation (stage III) occur there are disturbs in the spermatogenesis of the unsound bulls. The present proposition to cluster the stages of the spermatogenic cycle, forgives a practical method to evaluate the dynamic of germinative epithelium in bulls with different breeding soundness classification.

Key words: staging, spermatogenesis, synthetic bulls.

\section{INTRODUÇÃO}

Uma importante fonte de prejuízo nos sistemas de produção de bovinos de corte é o descarte de touros por alterações na qualidade do sêmen. Os touros de raças sintéticas são considerados inaptos à reprodução com maior freqüência que os de raças puras (CHENOWETH et al., 1996; MORAES et al., 1998; CHACÓN et al., 1999). Neste contexto, foi verificado que existem diferenças na qualidade do sêmen de touros de raças sintéticas em comparação com touros puros, quanto à potencialidade de recuperação dos indicadores

${ }^{1}$ Doutorando no Programa de Pós-graduação em Ciências Veterinárias, Faculdade de Veterinária, Universidade Federal do Rio Grande do Sul (UFRGS), Porto Alegre, RS

${ }^{2}$ Pesquisador Embrapa Pecuária Sul, Bagé, RS. Email:ferrugem@cppsul.embrapa.br

${ }^{3}$ Departamento de Patologia, Faculdade de Medicina, UFRGS. 
qualitativos do sêmen em seis meses de acompanhamento (HORN et al., 2002). No entanto, essas diferenças não foram detectadas quando touros puros e de raças sintéticas foram submetidos à degeneração testicular experimental induzida por dexametasona (HORN et al., 1999). O entendimento da etiologia deste maior percentual de descarte em touros oriundos de cruzamentos, pode ser alcançado através das seguintes abordagens: investigação dos tipos de cruzamentos entre as duas sub-espécies utilizados para a formação da raça sintética; estudos citológicos nos túbulos seminíferos, responsáveis diretos pela produção dos espermatozóides; e, ainda a investigação da capacidade de reabsorção de anomalias espermáticas pelo epidídimo.

A espermatogênese é um processo complexo, com inúmeras associações celulares não casuais. O ciclo espermatogênico do rato foi detalhadamente classificado em quatorze estádios, baseados na morfologia das espermátides (LEBLOND \& CLERMONT, 1952). AMANN (1962) descreveu para touros uma classificação mais simplificada com apenas oito estádios. As diferenças nas classificações entre espécies decorrem das células da linhagem espermática que são consideradas. Por exemplo, o estádio I em ratos é caracterizado por espermátides recém-formadas, o que eqüivale ao estádio V dos bovinos; já o estádio I dos bovinos é caracterizado pelo passo subsequente a espermiação, que eqüivale ao estágio IX em ratos.

A avaliação histológica é um instrumento útil para quantificar a espermatogênese, sendo que cerca de $10-11 \%$ dos túbulos seminíferos em estádio VIII, caracterizam um bovino com função gametogênica normal (AMANN, 1962). As freqüências encontradas para os demais estádios em touros de origem européia foram: $30 \%$ estádio I, $16 \%$ estádio II, $17 \%$ estádio III, $10 \%$ estádio IV, $2 \%$ estádio V, $6 \%$ estádio VI, $8 \%$ estádio VII. Neste sentido, RUSSEL et al. (1990) salientaram que a divisão do ciclo espermático em muitos estádios, apenas traz benefícios para uma pesquisa de extremo detalhe e que, em algumas circunstâncias, pode ser prudente agrupar ou selecionar apenas alguns estádios, visando facilitar as análises. Neste contexto, este estudo propõe agrupar o ciclo espermatogênico nas suas três fases características: a proliferativa ou espermatogonial, na qual as espermatogônias por mitose dão origem aos espermatócitos; a fase meiótica, que inclui as divisões reducionais; e a fase de diferenciação ou espermiogênica, que é caracterizada pela diferenciação das espermátides em espermatozóides (CLERMONT, 1972; RUSSEL et al., 1990). Os estádios do ciclo espermatogênico podem ser interrompidos por deficiente produção de alguns fatores de crescimento, como exemplo o EGF (TSUTSUMI et al., 1986). A produção de interleucinas pelas células de Sertoli também varia de acordo com os diferentes estádios do ciclo espermático (GÉRARD et al., 1992; SYED et al., 1993).

O objetivo deste estudo foi avaliar qual a freqüência de túbulos seminíferos nos diferentes estádios do ciclo espermatogênico em touros aptos e inaptos à reprodução de raças sintéticas de bovinos.

\section{MATERIAL E MÉTODOS}

Foram utilizados 12 touros Braford e 8 Brangus-Ibagé, de dois anos de idade, criados para reprodutores, provenientes de duas propriedades localizadas no sul do Rio Grande do Sul. Os animais foram previamente classificados quanto à condição reprodutiva, em função da qualidade do sêmen, na propriedade de origem em aptos e inaptos segundo as recomendações do MINISTÉRIO DA AGRICULTURA E ABASTECIMENTO (1996). Os touros foram abatidos no frigorífico por descarte zootécnico (aptos à reprodução) ou por má qualidade de sêmen (inaptos à reprodução). Logo após o abate, foi coletada uma porção de $2 \mathrm{~cm}^{3}$ de um testículo de cada animal, colocada em Bouin por 24 horas, a qual logo após foi transferida para álcool $70^{\circ} \mathrm{GL}$. Os fragmentos foram tratados em um processador automático de tecidos, para a posterior confecção dos blocos de parafina e cortes com espessura de $4 \mu \mathrm{m}$, submetidos à coloração de Hematoxilina-eosina.

Os touros Braford foram abatidos com intervalos variáveis da última avaliação seminal. Em função disso, no momento do abate, foi colhido sêmen da cauda do epidídimo para análise morfológica dos espermatozóides em lâmina corada e contraste de fase em formol salino. Estes animais foram novamente classificados em função do percentual de defeitos espermáticos encontrados na cauda do epidídimo. Para esta segunda classificação, foram considerados todos os defeitos espermáticos e gota citoplasmática proximal. Os touros foram então classificados em: Grupo A: dois touros aptos na propriedade de origem e com taxa inferior a $30 \%$ de defeitos na cauda do epidídimo postmorten; Grupo B: quatro touros inaptos na propriedade de origem e com taxa superior a $30 \%$ de defeitos na cauda do epidídimo post-morten; Grupo C: seis touros inaptos na propriedade de origem, porém com taxa inferior a $30 \%$ de defeitos na cauda do epidídimo postmorten. Já para os touros Brangus-Ibagé, apenas foi considerada a classificação da propriedade de origem (grupo $\mathrm{A}$, três touros aptos à reprodução e grupo B, cinco touros inaptos à reprodução). 
A análise dos estádios foi realizada com base na classificação de AMANN (1962), porém com o agrupamento dos estádios I e II; III e IV; V-VIII. Na tabela 1, estão apresentadas as associações celulares características de cada estádio utilizado para a avaliação da espermatogênese, comparativamente à proposta original. Este agrupamento dos estádios do ciclo permitiu a avaliação dos momentos do ciclo espermático que apresentam importância similar. O estádio I inclui como evento principal a mitose das espermatogônias em pré-leptoteno e espermatócito leptoteno e espermátides arredondadas ou levemente alongadas. O estádio II caracteriza a fase meiótica, quando ocorrem as divisões celulares reducionais $\mathrm{e}$ as células passam de espermatócitos para espermátides jovens. Os túbulos em estádio III representam a fase da maturação em que ocorre a transformação das espermátides em espermatozóides.

As comparações das freqüências dos diversos estádios da espermatogênese nos dois conjuntos raciais de touros, classificados quanto à condição reprodutiva foram efetivadas através do teste do Qui-quadrado.

\section{RESULTADOS E DISCUSSÃO}

$\mathrm{Na}$ tabela 2, são apresentados os resultados da quantificação dos estádios do ciclo do epitélio seminífero nos touros da raça Braford. Foi constatada diferença na freqüência dos estádios entre os três grupos de touros $(\chi 2=20,89 ; 4$ GL; $\mathrm{P}<0,05)$. Quando se considerou apenas os touros dos grupos A e B, ou seja, os animais avaliados duplamente quanto a morfologia espermática, na propriedade e no pos-morten, foi possível observar apenas diferenças significativas para os estádios II e III $(\chi 2=12,33 ; 1$ GL; $\mathrm{P}<0,05)$. No que diz respeito ao estádio II, caracterizado pelas meioses dos espermatócitos primários e secundários, resultando nas espermátides, o grupo A apresentou $22 \%$ e o grupo B, $27 \%$. O fato de os touros com baixa qualidade de sêmen apresentarem maior percentual destes estádios pode ser uma indicação de um bloqueio nas divisões celulares, decorrente de uma interrupção no ciclo celular neste ponto, ou ainda, pela inativação de determinados genes envolvidos na meiose (EDDY, 2002). Estes resultados reiteram os de AMANN (1962), que observou nos primeiros três quartos da espermatogênese, perdas que vão de $4 \%$ em touros jovens até $19 \%$ em touros maduros. O estádio III também foi diferente nos grupos A e B dos touros Braford, sendo que nestes, a perda foi respectivamente de $34 \%$ e $27 \%$. O touros do grupo A apresentaram um maior percentual de túbulos nos estádios finais do ciclo, o que pode estar relacionado a maior produção de células espermáticas normais, indicando, ainda, menores perdas na espermatogênese e consecução das etapas anteriores.

$\mathrm{Na}$ tabela 3, são apresentadas as freqüências de túbulos seminíferos avaliados nos touros Brangus-Ibagé. Apenas o estádio II foi diferente entre os grupos A e B, respectivamente com sêmen qualitativamente normal e alterado $(\chi 2=7,88 ; 2 \mathrm{GL}$; $\mathrm{P}<0,05$ ), apresentando $27 \%$ nos touros do grupo A e $32 \%$ nos do grupo B. Este resultado é semelhante ao constatado nos touros Braford, permitindo concluir que, no estádio I, não se expressam diferenças entre os touros classificados quanto à qualidade seminal, mesmo sendo este o estádio mais longo do ciclo (AMANN, 1962). Adicionalmente, é possível inferir que os fenômenos que ocorrem neste período do ciclo espermatogênico são menos dependentes de fatores ambientais ou genéticos, neste caso relacionados ao cruzamento entre as duas sub-espécies de bovinos. A ocorrência de menor freqüência de estádios II nos touros BrangusIbagé do grupo A, reitera os resultados obtidos nos touros da outra raça sintética, reforçando que a fase do ciclo em que ocorrem as meioses é a mais relacionada com a qualidade seminal. No entanto, neste conjunto racial, a fase de maturação apresentou freqüências

Tabela 1 - Critério de classificação para avaliação dos estádios ciclo espermático bovino.

\begin{tabular}{lcl}
\hline Presente estudo & $\begin{array}{l}\text { Classificação de } \\
\text { Amann (1962) }\end{array}$ & \multicolumn{1}{c}{ Características } \\
\hline I & I + II & $\begin{array}{l}\text { População celular composta de espermatogônias, espermatócitos jovens em fase de pré-leptóteno } \\
\text { e/ou leptóteno, espermatócitos velhos em paquíteno e uma geração de espermátides arredondadas ou } \\
\text { levemente alongadas. } \\
\text { População celular composta de espermatócitos jovens em leptóteno e zigóteno, espermatócitos } \\
\text { velhos em paquíteno ou diplóteno, células em divisão meiótica e/ou espermatócitos secundários e } \\
\text { espermátides alongadas. } \\
\text { População celular composta de espermatogônias, espermatócitos em paquíteno, espermátides jovens } \\
\text { arredondandas e espermátides alongadas justapostas as células de Sertoli ou prontas para } \\
\text { espermiação. }\end{array}$ \\
III & III + IV &
\end{tabular}

Ciência Rural, v. 33, n. 6, nov-dez, 2003. 
Tabela 2 - Número e freqüência de estádios do ciclo do epitélio seminífero em 3496 túbulos avaliados em 12 touros Braford classificados quanto à fertilidade potencial.

\begin{tabular}{lccc}
\hline Grupo de touros & $\begin{array}{c}\text { Estádio I } \\
\mathrm{N}^{\circ}(\%)\end{array}$ & $\begin{array}{c}\text { Estádio II } \\
\mathrm{N}^{\circ}(\%)\end{array}$ & $\begin{array}{c}\text { Estádio III } \\
\mathrm{N}^{\circ}(\%)\end{array}$ \\
\hline A & $227(44)$ & $114(22)$ & $175(34)$ \\
B & $548(46)$ & $323(27)$ & $318(27)$ \\
C & $720(40)$ & $528(29)$ & $546(30)$ \\
\hline
\end{tabular}

Tabela 3 - Número e freqüência de estádios do ciclo do epitélio seminífero em 2392 túbulos avaliados em oito touros Brangus-Ibagé classificados quanto à fertilidade potencial.

\begin{tabular}{lccc}
\hline Grupo de touros & $\begin{array}{c}\text { Estádio I } \\
\mathrm{N}^{\mathrm{o}}(\%)\end{array}$ & $\begin{array}{c}\text { Estádio II } \\
\mathrm{N}^{\circ}(\%)\end{array}$ & $\begin{array}{c}\text { Estádio III } \\
\mathrm{N}^{\circ}(\%)\end{array}$ \\
\hline $\mathrm{A}$ & $442(49)$ & $239(27)$ & $216(24)$ \\
$\mathrm{B}$ & $696(47)$ & $478(32)$ & $321(21)$ \\
\hline
\end{tabular}

semelhantes entre os dois grupos. Contrastando com o grupo de touros Braford, cuja diferença nesta fase pode estar relacionada aos tipos de cruzamentos utilizados para a formação dessa raça sintética. Uma diminuição na produção de espermátides redondas (estádio II) também foi identificada em ratos que tiveram a glândula submandibular retirada (principal órgão secretor de EGF - epidermal growth factor), sugerindo que a falta deste fator de crescimento é diretamente relacionado na divisão celular (TSUTSUMI et al., 1986). O TGFa (transforming growth factor) é biologicamente e estruturalmente semelhante ao EGF e estes fatores estão relacionados à proliferação celular no testículo (LEVINE et al., 2000). A deficiência destes fatores, produzidos pelas células de Sertoli e germinativas (SKINNER et al., 1991), pode estar relacionada com a alteração na qualidade seminal e freqüência diferencial dos estádios II no ciclo espermático.

\section{CONCLUSÃO}

O estádio inicial do ciclo espermatogênico apresenta funcionalidade similar em touros de raças sintéticas classificados quanto à qualidade seminal em normais e alterados. Nas fases em que ocorrem as divisões meióticas (estádio II) e a maturação das espermátides (estádio III) manifestam-se as alterações na espermatogênese que respondem pela classificação diferencial dos touros. O uso do presente agrupamento de estádios do ciclo espermatogênico proporciona uma nova e prática maneira para avaliar a cinética do epitélio germinativo em touros aptos e inaptos à reprodução.

\section{REFERÊNCIAS BIBLIOGRÁFICAS}

AMANN, R.P. Reproductive capacity of dairy bulls. III. The effect of ejaculation frequency, unilateral vasectomy and age on spermatogenesis. The American Journal of Anatomy, v.110, p.49-78, 1962.

CHACÓN, J.C. et al. Breeding soundness evaluation of extensively managed bulls in Costa Rica. Theriogenology, v.52, p.221-231, 1999.

CHENOWETH, P.J. The assessment of sexual performance in young Bos taurus and Bos indicus beef bulls. Applied Animal Behaviour Science, Amsterdam, v.48, n.3-4, p.225-236, 1996.

CLERMONT, Y. Kinetics of spermatogenesis mammals: seminiferous epithelium cycle and spermatogonial renewal. Physiology Reviews, v.52, p.198-236, 1972.

EDDY, E.M. Male germ cell gene expression. Recent Progress in Hormone Research, v.57, n.1, p.103-128, 2002.

GERARD, N.; SYED, V.; JEGOU, B. Lipopolysaccharide, latex beads and residual bodies are potent activators od Sertoli cell interleukin-1a production. Biophys Biochem Res Commun, v.185, p.154-161, 1992.

HORN, M.M.; MORAES, J.C.F.; GALINA, C.S. Qualidade do sêmen de touros das raças Aberdeen Angus e BrangusIbagé em frente à degeneração testicular experimental induzida por dexametasona. Ciência Rural, v.29, n.3, p.523-526, 1999.

HORN, M.M.; MORAES, J.C.F.; MACIEL, M.N. Variação temporal da qualidade seminal em touros de genótipo puro europeu e sintético derivado. Revista Brasileira Reprodução Animal. v.26, n.4, p.324-330, 2002.

LEBLOND, C.P.; CLERMONT, Y. Spermiogenesis of rat, mouse, hamster and guinea pig as revealed by the "periodic acid-fuchsin sulfurous acid" technique. The American Journal of Anatomy, v.99, p.391-413, 1952.

LEVINE, E. et al. Role of tranforming growing factoralpha and the epidermal growth factor receptor in embryonic rat testis development. Biology of Reproduction, v.62, p.477-490, 2000.

MINISTÉRIO DA AGRICULTURA E ABASTECIMENTO. Normas para sêmen e Centrais. Portarias n. 25 e 26 de 05 de setembro de 1996. Diário Oficial da União, Brasília, Seção 1, n.174, 06 de set de 1996.

MORAES, J.C.F.; HORN, M.M.; ROSADO, A. Avaliação andrológica em touros: qualidade dos indicadores da aptidão reprodutiva em distintos grupos raciais. Ciência Rural, v.28, n.4, p. 647-652, 1998.

SKINNER, M.K. Cell-cell interactions in the testis. Endocrine Reviews, v.12, p.45-77, 1991.

SYED, V. et al. Identification, ontogeny, and regulation of an interleucin-6-like factor in the rat seminiferous tubule. Endocrinology, v.132, n.1, p.293-299, 1993. 
RUSSEL, L.D. et al. Histological and histopathological evaluation of the testis. Clearwater: Cache River, 1990. $286 \mathrm{p}$.
TSUTSUMI, O.; KURACHI, H.; OKA, T. A physiological role of epidermal growth factor in male reproduction function. Science, v.233, p.975-977, 1986. 